\title{
PREDICTING A FIRM'S FORECASTING ABILITY: THE ROLES OF ORGANIZATIONAL ILLUSION OF CONTROL AND ORGANIZATIONAL ATTENTION
}

\author{
RODOLPHE DURAND* \\ EM-Lyon, Ecully, France
}

\begin{abstract}
Recent research shows that forecasting ability is an organizational distinctive competence. We propose and test a model accounting for interfirm differences in forecasting ability. After controlling for reciprocal effects, we find that two principal firm-level factors (i.e., organizational illusion of control and organizational attention) influence both bias and magnitude of errors in estimates. High organizational illusion of control increases positive forecast bias. As for organizational attention, higher relative investments in market information appear to reduce positive forecast bias and magnitude of errors; they also moderate forecast bias due to illusion of control. Finally, higher relative investments in employee capability increase both negative forecast bias and, unexpectedly, magnitude of errors for the majority of observed cases. Copyright (c) 2003 John Wiley \& Sons, Ltd.
\end{abstract}

\section{INTRODUCTION}

Organizations rely extensively on forecasts in making strategic decisions. The performance of a firm is influenced by its ability to match its resource allocation pace to the anticipated changes of its environment (Eisenhardt and Martin, 2000). Firms that overinvest because of positive forecast that does not materialize generate higher fixed costs and overheads, which reduces performance. Firms that underestimate favorable changes cannot keep up with demand and technological evolution, and as a result lose competitive edge. Hence, forecasting ability appears to be a distinctive organizational capability (Makadok and Walker, 2000).

In organizational life, several factors that can negatively affect judgment cause organizations to

Key words: forecasting ability; illusion of control; attention; resources

* Correspondence to: Rodolphe Durand, EM-Lyon, 23 Av. Guy de Collongue, 69132 Ecully, France.

E-mail: rdurand@em-lyon.com commit errors in forecasting. First, cognitive biases impair decision-makers' abilities to select optimal choices (Barnes, 1984; Schwenk, 1984; Clapham and Schwenk, 1991). Second, routines as preprogrammed sequences of behavior short-circuit individuals' autonomous judgments (Nelson and Winter, 1982; Teece, Pisano, and Shuen, 1997). Third, dominant logic orients individuals' vision, resulting in blind spots and escalation of commitment (Prahalad and Bettis, 1986; Staw and Ross, 1987). In short, individuals' intrinsic limitations may cause individuals and hence the organizations they work for to commit forecast errors; i.e., may undermine a firm's forecasting ability.

However, such limitations may not fully explain the intraindustry variance in organizational forecasts, and theory has seldom considered the influence of an organization's characteristics on its forecasting ability. The possibility that organizations might also condition forecasting ability needs to be investigated. Hence, we address two research questions in this paper: First, what are a firm's 
characteristics that influence its forecasting ability? Second, how do these characteristics impact forecasting biases and magnitude of errors?

This paper attempts to fill three gaps in the current literature in terms of (1) level of analysis, (2) balance in the study of estimation biases, and (3) examination of interaction between factors impacting forecasting errors. First, highlighting organizational influences complements the now classical theory of errors in strategic decision making, predominantly based on individuals' biases (Kahneman and Tversky, 1984; Das and Teng, 1999). Second, an explanation of estimation (in)accuracy based on a firm's characteristics has to consider the different relationships between the explanatory factors of a firm's inaccurate estimates, error direction, and error value (King and Zeithaml, 2001). Shedding light on these issues helps explain strategic behavior (Mosakowski, 1998a), as well as corrects a tendency in current research toward the study of overconfidence and hubris rather than pessimism and underestimation (Hayward and Hambrick, 1997; Coff, 1999). Third, while evidence exists of organizational effects on estimation capability, there is a need to study simultaneously potential countervailing effects on forecasting ability (McNamara and Bromiley, 1997; Makadok and Walker, 2000).

We propose and then test hypotheses that link organizational characteristics, principally organizational illusion of control and organizational attention, to an organization's estimation biases. We apply our hypotheses to the forecast of positive factors from the firm perspective and use industry growth as our parameter of estimation. The results (from 785 firms in 36 industries) greatly support our hypotheses and demonstrate: (1) a path dependency between past behaviors and forecasting errors; (2) the influence of organizational illusion of control which increases positive forecast bias; (3) the improved accuracy in forecasts due to organizational attention which reduces the magnitude of error; and (4) the moderating effect of organizational attention on biases associated with illusion of control.

\section{THEORY BACKGROUND}

Forecast accuracy is essential to a firm's success and performance (Barney, 1986; Makadok and
Walker, 2000). Evidence shows that organizational context is a major factor influencing a firm's estimation capability (Bateman and Zeithaml, 1989; McNamara and Bromiley, 1997; Mosakowski, 1998b; Makadok and Walker, 2000; King and Zeithaml, 2001). According to McNamara and Bromiley (1997) the influence of organizational characteristics on firm perception of environmental factors like risk is diffused throughout the company. They examine which biases (individual or organizational) prevail when evaluating risky projects in the loan bank industry. Individual biases are related to length of customer relationships with the bank (bank branch managers prefer known clients), loan size (bank branch managers prefer smaller loans), and industry excitement (bank branch managers favor high-tech projects). Organizational biases, on the other hand, consist of attracting new customers, signing large loans, considering prior performance of the branch, and using routinized forms of evaluation. Their results show that when organizational and personal biases pull the decision-maker in opposite directions, organizational influences tend to dominate.

Elsewhere, Carleton, Chen, and Steiner (1998) demonstrate that financial market analysts employed by brokerage companies appear to significantly inflate their recommendations relative to analysts from nonbrokerage companies, leading to inferior predictions of future stock performance. They attribute this estimation bias to the fact that the former simultaneously aim at capturing underwriting business. From Sutcliffe and Huber's (1998) study of TMT perceptions, belonging to the same organization significantly shapes top executives' common perception on five environmental dimensions: instability, munificence, complexity, hostility, and controllability. Notably, firm affiliation accounts for a great deal of the variance in these five characteristics, much more than industry affiliation. Accordingly, McNamara and Vaaler (2000) find evidence of the influence of competitive positioning and rivalry on the sovereign risk assessments provided by rating agencies.

Moreover, every organization (whose unique history accounts for interfirm estimation differences) models how it perceives the environment through its successful and unsuccessful actions (Prahalad and Bettis, 1986). For example, in the 'escalation of commitment' syndrome, exogenous information transformed in an untimely fashion leads to a succession of inappropriate decisions 
(Staw and Ross, 1987). Accordingly, Garud and Rappa (1994) demonstrate how organizational cognition, static representations, and interorganizational settings explain the anticipated evolution of the cochlear implant industry. Recently, Tripsas and Gavetti (2000) showed how top management's beliefs constrained Polaroid's market position more than traditional path-dependent capability phenomena (Teece et al., 1997).

In brief, the evolutionary tradition coupled with the cognitive theory of collective actions show how past decisions and past performance condition the organization's ability to forecast exogenous indicators. There is a tendency, when extrapolating the future from the past, to ignore the 'regression toward the mean' phenomenon (Greve, 1999). When one period's performance is above the mean, the next period's is likely to be lower, assuming a normal distribution of performance (since the probability mass below the mean and between current performance and the mean is greater than 50\%). For high performers, their current performance includes some randomness that positively influenced their results - randomness which by definition may not occur the following period. Falsely associating a future situation with past changes induces a partial representativeness of the information used in forecasts that leads to inaccurate predictions (Tversky and Kahneman, 1974). As a consequence of the ignorance of this phenomenon, we expect that firms experiencing positive changes in internal performance indicators will positively bias their forecasts, while those with negative changes in these indicators will negatively bias their forecasts.

Hypothesis 1: There is a positive association between change in past internal performance indicators and forecast biases.

\section{THEORETICAL MODEL AND FURTHER HYPOTHESES}

\section{Illusion of control and attention problems}

In one of the seminal works on forecasting biases, in addition to false past change-anticipated situation association, Schwenk (1984) distinguishes two principal simplification processes in the forecasting stage of strategic decision making: illusion of control and attention problems.
First, illusion of control causes an inaccurate assessment of risks (Langer, 1975; Schwenk, 1984). Basically, the higher the perception of control, the higher the likelihood of underestimating risks (Schwenk, 1986). In other words, a manager's positive misconceptions of control will lead to overestimating the ratio of success for a task. Illusion of control counters the natural tendency for individuals to underestimate positive information and overestimate negative information, which normally results in capped forecasts likely to reduce the odds of overestimation (Langer, 1975; Schweitzer and Cachon, 2000). According to Sutcliffe and Huber (1998), controllability is the dimension most linked to firm affiliation, confirming that a firm's perception of control is tightly linked to its characteristics. A related strand of literature concerns the notion of overconfidence and its consequences. Overconfidence (or hubris), which occurs when a manager is sure that decision outputs are accurate when they are not (Duhaime and Schwenk, 1985; Bourgeois, 1985), is the failure to know the limits of one's current knowledge due to stress, ambiguity, and complexity (Barnes, 1984; Halman and Keizer, 1994). Illusion of control and overconfidence lead decision-makers to misjudge exogenous variables, like the market value of target companies in acquisitions (Hayward and Hambrick, 1997). ${ }^{1}$

Second, attention problems reduce an individual and organization forecasting ability. Indeed, poor attention to and description of environmental conditions lead to the rejection of otherwise relevant alternatives (Yates, Jagacinski, and Faber, 1978). In their study of bank loans to business borrowers, McNamara and Bromiley (1999) identify organizational attention as a factor leading executives to mistake the risk-return relationship. Top executives seem to be attentive to poor but familiar informative indicators like interest rates instead of to more complex risk-adjusted expected returns measures. Accordingly, Das and Teng (1999) distinguish three consequences of attention problems: focus on limited targets, exposure to limited alternatives, and insensitivity to outcomes. Focus on

\footnotetext{
${ }^{1}$ Testing two competing views of the effects of overconfidence on the performance of product introductions, Simon, Houghton, and Savelli (2000) show that while overconfidence could lead to seemingly faulty assumptions, enactment can prove them justified. This underlines the importance of studying the link between an organization's characteristics, its estimation ability, and its decisions.
} 
limited targets prevents the organization from perceiving the full range of possibilities. Exposure to limited alternatives means that the organization does not envisage alternate scenarios, resulting in sample bias. Insensitivity to outcome, elsewhere called adjustment and anchoring problems (Schwenk, 1984; Bromiley, 1987), refers to the imperfect readjustment of estimates despite receiving more accurate information (i.e., final estimates are biased toward initial estimates). All lead to inaccurate estimates and demonstrate a deficiency in organizational attention.

In this paper, we prolong the research on illusion of control and attention problems at the organizational level. Below, we examine how organizational illusion of control and organizational attention influence a firm's forecasting biases and errors from a positive perspective (e.g., growth). Note that the proposed hypotheses should be reversed when estimating adverse factors (e.g., recession).

\section{Sources of organizational illusion of control and forecast bias}

According to Hayward and Hambrick (1997), the two principal sources of illusion of control are (1) perceived ability to influence the environment and (2) organizational self-perception. First, from a firm-focused perspective, the ability to influence the environment and to control the future depends on a firm's resources and investments in dynamic capabilities (Penrose, 1959; Barney, 1986, 1991; Teece et al., 1997; Eisenhardt and Martin, 2000). However, while high relative investments in dynamic resources can positively affect a firm's ability to control the future, they can also influence its forecasts. Greve $(1996,1998)$ states that organizations, due to cognitive limitations, mimetically adopt business practices based on allegedly positive effects resulting from a competitor's actions, although lacking information on the results of those actions. Accordingly, even without observing actual results, increasing investments in resources more than one's competitors reinforces the feeling of doing better than they do, leading to positively biased estimates. Investments in dynamic resources (like $\mathrm{R} \& \mathrm{D}$, recruiting visible managers, and so forth), which are observable and relevant for actual control (Greve, 1998: 970), are likely to underlie a positive assessment of the future. Higher relative investments give credit to the perceived controllability of the environment by the organization (Wood and Bandura, 1989). Thus, the more a firm spends on dynamic resources relative to its competitors, the more it is likely to positively bias its forecasts. Therefore:

\section{Hypothesis 2: High relative investments in dynamic resources bias forecasts positively.}

The second source of organizational illusion of control, a firm's self-perception (Wood and Bandura, 1989; Hayward and Hambrick, 1997), is an extension of perceived self-efficacy that Bandura (1977) identified for individuals. Perceived self-efficacy is the 'beliefs in one's capabilities to mobilize the motivation, cognitive resources, and courses of action needed to meet given situational demands' (Wood and Bandura, 1989: 364). Organizational self-perception concerns, for instance, a firm's advantages, alignment or environmental fit (Powell, 1992). In their study on 224 executives' perceptions (from 17 organizations, either textile manufacturers or hospitals), King and Zeithaml (2001) find a negative association between biased perceptions of the firm advantage-performance link and effective performance (both at the top- and middle-manager levels). Misconception of a firm's own advantages may lead to severely biased estimations (Wood and Bandura, 1989; Matute, 1996; see also Tripsas and Gavetti's, 2000, Polaroid study). As such, organizations with high perceived advantages are likely to exaggerate their estimations (Duhaime and Schwenk, 1985; Clapham and Schwenk, 1991; Coff, 1999), resulting in positive forecast biases. Consequently:

\section{Hypothesis 3: A firm's high self-perception biases forecasts positively.}

\section{Organizational attention and accuracy}

Where and how much relative to its competitors a firm focuses its attention impacts its forecasting ability (Schwenk, 1984; Bromiley, 1987; Das and Teng, 1999). Ocasio (1997: 204) stresses that 'the focusing of attention by organizational decision makers allows for enhanced accuracy, speed, and maintenance of information-processing activities, facilitating perception and action for those activities attended to.' As stated by Cockburn, Henderson, and Stern (2000: 1142): 'Ex post, it is clear that some firms actively identify, interpret, and act 
upon early signals from their external and internal environment, and so position themselves to effectively exploit these opportunities well in advance of others' demonstration of the pay-off from the strategies which emerge later on as best practices.' Hence, we study the connections between a firm's focus on external and internal information and its forecasting ability.

First, a firm's ability to incorporate external information increases its odds of accurately forecasting environmental evolutions (Corner, Kinicki, and Keats, 1994; Ocasio, 1997). Thomas, Clark, and Gioia (1993) show the relationship between levels of external information used by managers and managers' abilities to positively interpret their environments. Using hospitals, their path analysis related scanning, interpretation, and action to performance. In this case, external information consisted mostly of industry and marketing surveys that helped hospitals refine their evaluations of industry scenarios. All sources of market information (e.g., trends in customers' needs and tastes, retailers' aspirations, and competitors' situations) contribute to a firm's forecasting ability (Daft and Weick, 1984; Bateman and Zeithaml, 1989; Brews and Hunt, 1999). Marketing expenditures characterize a firm's focused attention on its external environment (see Daft and Weick's 'organizational intrusiveness;' Corner et al., 1994). Thus, we expect that high investments in market information relative to competitors, as indicators of a firm's strong focus of attention on external information, reduce the magnitude of forecast errors (i.e., improve forecasting ability):

Hypothesis 4: Relative investments in market information negatively influence the magnitude of forecast errors (i.e., positively influence forecast accuracy).

To articulate and distribute internal information to its employees, a company must focus its attention on employee motivation and capability (Sutcliffe, 1994; Grant, 1998). For instance, Henderson and Cockburn (1994) show that in the pharmaceutical industry absorptive capacity is closely associated with a firm's commitment to knowledge diffusion inside the organization. Accordingly, for Ocasio (1997: 202), improving a firm's forecasting ability is related to its ability to focus the attention of its decision makers on the appropriate issues and answers,' which is directly related to employee capability, managerial rules and prescriptions (Mosakowski, 1997, 1998a). A capable manager deciphers and distributes multiple pieces of information to the appropriate beneficiaries (Ocasio, 1997). Therefore, high investments in employee capability relative to competitors, as a comparatively greater focus on internal information, should reduce the magnitude of error (i.e., improve forecast accuracy):

\section{Hypothesis 5: Relative investments in employee capability negatively influence the magnitude of forecast errors (i.e., positively influence forecast accuracy).}

While organizational illusion of control increases positive forecast bias, organizational attention diminishes both positive forecast bias and magnitude of errors. The next question of interest logically concerns the interaction of organizational attention with illusion of control. Organizational attention properly directed improves accuracy and provides a better evaluation of a firm's strengths and weaknesses, thereby reducing the firm's propensity to overrate both itself and its control on environmental factors. Organizational attention leads to more objective perceptions of company potentialities. Hence, a broader organizational attention towards external and internal sources of information should moderate biases associated with organizational illusion of control:

\section{Hypothesis 6: Organizational attention reduces the illusion of control biases on error magnitude.}

\section{METHODS}

Three problems have to be overcome in the empirical analysis. First, we must be able to assess relative investments, which raises the issue of the size of industry subsamples. Second, we must be cautious in agreeing on intraindustry firms' perceptions - if not, variations in forecasts could be driven by intraindustry sample heterogeneity. (These two issues are addressed in the 'Data' section.) Third, we face the risk of circular relationships between dependent and independent variables (addressed in the 'Data analysis procedures' section.) Our forecasts deal with industry growth; 
errors are the difference between a firm's industry growth estimate (IGE) and the accurate growth rate.

\section{Data}

The Bank of France, the French central bank, provided our data. Initiated in 1993, the 'Sesame' data collection project has enabled the Bank to complement its financial databases with more qualitative and strategic information. Bank econometricians generate a representative sample of firms operating in manufacturing industries each year. Next, professional interviewers meet with firms' CEOs and administer a detailed computerized questionnaire dealing with the strategy formulation process, industry environment, and firm competitive position (no merchant or power relations whatsoever exist between the Bank and the interviewed companies). The database represents a very reliable sample of French manufacturing industries and has been used in several previous empirical studies (Amburgey and Dacin, 1997; Cool and Henderson, 1998). Typical of the French economic landscape, the great majority of firms surveyed are small to medium sized. In 1996, our survey year, 90 percent of 2145 firms had 30-1500 employees.

We controlled for two risks. First, in order to compare every firm's investments relative to average investments in its industry, we needed to calculate reliable industry averages. Indeed, the variance of the distribution of a sample mean decreases as the sample size increases (Wonnacott and Wonnacott, 1972) and some industries in our sample contained only a few firms. In order to minimize the presence of outliers and compare a firm's situation with a realistic industry average, we selected 4-digit NACE industries ${ }^{2}$ for which there were at least 15 firms, a widely used procedure, especially in previous Bank of France dataset studies (Cool and Henderson, 1998). After this first selection, 1750 firms representing 84 industries remained.

Second, we verified the presence of intraindustry commonality of perception before testing our hypotheses. Industry measures based on 4digit SIC codes or equivalents are plagued with aggregation biases (e.g., FTC's data, Compustat, perhaps our data - see Scherer and Ross, 1990).

${ }^{2}$ NACE is the European classification of industries, comparable to American SIC codes.
Because these surveys lump together noncompeting products, firms' perceptions of their industries may vary greatly inside an industry code (Lubatkin et al., 2001); firms may be part of the same industry code and not be competitors. Therefore, we calculated kappa statistics on interfirm agreements when assessing perceptions of industry forces (bargaining power of suppliers and customers, barriers to entry, industry rivalry - all evaluated on a 5point Likert scale) and industry key success factors (binary answers for factors like price, quality, technical performance, reputation, responsiveness, services, and proximity). ${ }^{3}$ The 'kappa statistics measure of agreement' is scaled to 0 when the amount of agreement is that expected to be observed by chance and to 1 when there is perfect agreement among evaluators. Landis and Koch (1977) suggest that above 0.20 kappa statistics represent a fair level of agreement among observers. Therefore, we disregarded industries with kappa statistics below 0.20 .

The final sample, which consists of 785 firms in 36 industries, indicates that we found agreement within the 4-digit NACE codes for less than half of the industries and suggests the relatively high heterogeneity of industrial classifications. Differing evaluations of industry performance drivers indicates that some respondents, while belonging to the same NACE code, did not operate in the same competitive sector. As we did not want this heterogeneity to be a driver of estimate variance, we excluded those industries. We controlled for sample bias problems: at each stage of the sample selection process, no significant bias appeared in terms of size or performance indicators. In addition, testing our models with the 84 original industries showed minimal differences. Narrowing the sample improves fit statistics (system-weighted $R^{2}$ ) and gives better $t$-values for the coefficients of our independent variables. Finally, using an even more stringent threshold (kappa greater than $60 \%$ ), we tested the models on the 10 remaining industries and got very close results also. Restricting the sample to 36 industries both prevented us

\footnotetext{
${ }^{3}$ Interclass correlation coefficients could also have been used for selecting industries. However, kappa statistics evaluate the significance of observed agreement among raters relative to random agreement. In addition, interclass correlation is appropriate when the variables lie on an ordinal scale, while kappa statistics do not need this property (as a matter of fact, some of the evaluated variables were dichotomous).
} 
from keeping companies with heterogeneous perceptions on their environments and provided robust results for the magnitude and the direction of the independent variables' effects on estimating errors.

\section{Operationalizing variables}

\section{Dependent variables}

We obtained estimates from data collected by the Bank of France on firms' predictions of 1997 NACE-4 industry growth rates. We collected the actual 1997 growth rates for our 36 industries from national statistics. We used the standardized value of two dependent variables to test our hypotheses. The first dependent variable is the straight error (i.e., the difference between each firm's IGE and actual 1997 industry growth rate), which measures the forecast bias (i.e., the direction of the error). Our second dependent variable, the absolute value of straight errors, measures the magnitude of the error (i.e., forecasting accuracy).

\section{Independent variables}

First, for past variation of internal performance indicators (Hypothesis 1), we used the variation of production over the last 2 years. 'Past-Prod' corresponds to the percentage of change in firm production over the last 2 years.

Second, for dynamic resources (Hypothesis 2 ), we used a firm's investment in R\&D relative to industry average $R \& D$ expenditures (RelativeR\&D). Therefore, RelativeR\&D is the difference between a firm's R\&D expenditures expressed as a percentage of total sales and the calculated average percentage of $R \& D$ expenditures at the industry level.

Third, for self-perception (Hypothesis 3), we used a weighted average of a firm's perceived strengths on identified industry key success factors (SelfPerception). This variable contains characteristics common to formerly used metrics. Industry key success factors are similar to previous studies (Beyer et al., 1997; Chattopadhyay et al., 1999) and consist of cost, quality, technical performance, reputation, responsiveness, services, and proximity (see Appendix). The method used to calculate this item consists of a ratio between a sum of the respondents' grade and the best grade possible, i.e., 5 (e.g., Knight et al.'s, 1999, study on consensus or, in the same spirit while applied to a different construct, the weighted average of the individuallevel complexity measures as used by McNamara, Luce, and Thompson, 2002). The self-perception variable ranges from 0 to 1 , and equals 1 when responses on the relative strength of the firm vs. its competitors are maximum and coincide with industry key success factors identified by the firm.

Fourth, for investment in market information (Hypothesis 4), we calculated the difference between the expenditures a firm devoted to gathering market information (expressed as a percentage of sales) relative to its competitors' expenditures (Rel-Market-Info).

Finally, for investment in employee capability (Hypothesis 5), we calculated the difference between a firm's investments in education and training (expressed as a percentage of overall salary expenses) relative to the average expenditure made by other firms in the same industry (Rel-Educ-Invst).

\section{Control variables}

We introduced two control variables at the firm level: size and diversification. 'Size' is the logarithm of a firm's 3-year average number of employees. (We include size as a control variable because IGE may be partially dependent on firm size.) In fact, a large firm is likely to imagine it commands more industry growth than a small company. 'Diversified' is a dichotomous variable, which equals 0 when more than 90 percent of a firm's sales come from one business and equals 1 otherwise. We include 'diversified' as a control variable since a firm's structure can have an impact on estimates (Carleton et al., 1998).

We also introduced two industry-level control variables. First, we control for ease of industry forecasting. ${ }^{4}$ Forecasting industry growth is easier in stable or stagnant industries than in emerging ones. In order to assess an ex ante industry ease of forecasting, we used $\varepsilon$ from the following equation, calculated for each of the 36 industries:

$$
\mathrm{IG}_{i, t}=\alpha+\beta \mathrm{IG}_{i, t-1}+\varepsilon_{i, t}
$$

with IG for industry growth, where $i$ indexes the industry $(i=1, \ldots, 36)$ and $t$ indexes the years 1995 to 1997 . The residual $\varepsilon$ represents that portion of industry growth not explained as

\footnotetext{
${ }^{4}$ We thank an anonymous reviewer for suggesting this control.
} 
a function of the industry growth rate ( $\alpha$ and $\beta$ coefficients). Since we name the variable 'Ease of forecasting,' we reverse error magnitude by taking the multiplicative inverse of the average absolute value of $\varepsilon$ (since a high $\varepsilon$ indicates a large deviation-i.e., uneasy forecasting).

Second, 'concentration' represents the degree of concentration in the industry (market share of the four major competitors) and might be related to easier forecastability of industry growth.

\section{Data analysis procedures}

Because circular relationships may exist between investments in R\&D, market information, education, and IGE, we must note that IGE may have a reciprocal effect on a firm's relative level of expenditures. In fact, when a firm either undervalues or overvalues industry potential, its investments in resources will be naturally either lower or higher relative to those of its competitors. A codetermination process is at stake. Therefore, the model has to incorporate the reciprocal relationships between IGE and level of expenditures. The complete set of equations to be tested twice (once with IGE straight error and once with absolute error) is as follows:

$$
\begin{aligned}
& \text { ErrorIGE }=\alpha_{1}+\beta_{1} \cdot \text { PastProd }+\beta_{2} \cdot \text { RelativeR } \& \mathrm{D} \\
& \quad+\beta_{3} \cdot \text { SelfPerception }+\beta_{4} \cdot \text { Rel-Market-Info } \\
& \quad+\beta_{5} \cdot \text { Rel-Educ-Invst }+\beta_{6} \cdot \text { Size } \\
& \quad+\beta_{7} \cdot \text { Diversified }+\beta_{8} \cdot \text { EaseofForecasting } \\
& \quad+\beta_{9} \cdot \text { Concentration }+\varepsilon \\
& \text { RelativeR } \& D=\alpha_{2}+\chi_{2} \cdot \text { ErrorIGE } \\
& \quad+\delta_{2} \cdot \text { IndControls }+\varepsilon_{2} \\
& \text { Rel-Market-Info }=\alpha_{3}+\chi_{3} \cdot \text { ErrorIGE } \\
& \quad+\delta_{3} \cdot \text { IndControls }+\varepsilon_{3} \\
& \text { Rel-Educ-Invst }=\alpha_{4}+\chi_{4} \cdot \text { ErrorIGE } \\
& \quad+\delta_{4} \cdot \text { IndControls }+\varepsilon_{4}
\end{aligned}
$$

with ErrorIGE being the straight error for Model 1 and the absolute value of error for Models 2 and 3 .

In Equation 1, according to Hypotheses 1, 2, and $3, \beta_{1}, \beta_{2}$, and $\beta_{3}$ should be positive for Model 1 using straight error as the dependent variable. According to Hypotheses 4 and 5, $\beta_{4}$ and $\beta_{5}$ should be negative for Model 2 using absolute error as the dependent variable. By adding interaction terms (RelativeR\&D $\times$ Rel-Market-Info, RelativeR\&D $\times$ Rel-Educ-Invst, SelfPerception $\times$ Rel-Market-Info, and SelfPerception $\times$ Rel-EducInvst) in Model 2, we obtain Model 3; all the $\beta$ of the interaction terms should be negative (according to Hypothesis 6).

In Equations 2-4, errors in IGE (straight or absolute) are also considered as explanatory variables of RelativeR\&D, Rel-Market-Info, and RelEduc-Invst. While it makes clear sense in Model 1 that straight errors may have an effect on investment decisions (Equations 2-4), it is less obvious that the absolute value of errors impacts these investments in Models 2 and 3. From a model estimation perspective, it is logical to use the absolute error in Models 2 and 3, but it is less so the case from a theoretical perspective. Therefore, we created a fourth model where the dependent variable is the absolute errors (like in Models 2 and 3) but for which ErrorIGE in Equations 2-4 is the straight error. For all models, $\delta$ parameters correspond to the effect of industry controls (proxies of the 'five forces' that pressure each industry) on firm investments. Better than industry dummies, ${ }^{5}$ these variables describe a general industry situation in relation to a firm's behavior (see Appendix). We also added 'Ease of forecasting' as a sixth industry control variable.

Equations 1-4 form a simultaneous system that can be estimated using a three-stage-leastsquare (3SLS) model, one of the most commonly used methods. OLS estimates of ErrorIGE would be biased because of the responsiveness of the resource variables to the dependent variables. System estimating methods cope with this problem and estimate all the identified structural equations together, instead of estimating the structural parameters of each equation separately (Theil, 1971; Pindyck and Rubinfeld, 1981). More specifically, 3SLS estimators are asymptotically more efficient than 2 SLS. Especially, 3SLS is recommended when the sample size is large, and when there is suspicion of correlation between

\footnotetext{
${ }^{5}$ Despite the fact that the 'five forces model' was developed to explain industry profitability, it describes industries better than our 36 dummies. It is interesting to use the five forces as variables for controlling industry structure effects on firm behavior. Accordingly, Mosakowski and McKelvey (1997: 80-81) suggest controlling for 'severity' of the environment when studying the effects of firm investments in resources.
} 
the disturbances in the different equations of the system (Kennedy, 1998).

\section{RESULTS}

Table 1 presents the descriptive statistics and the correlation matrix of the model variables. No variable exhibits distribution or correlation problems.

Table 2 shows the results. Model 1 uses straight error as the dependent variable and estimates the effects of independent variables on forecast bias. Models 2-4 use the absolute value of errors as the dependent variable. Model 3 includes the interaction terms. Model 4 uses the straight error as an independent variable in Equations 2-4. Systemweighted $R^{2}$ for Models 1, 2, 3, and 4 are 34.4 percent, 28.7 percent, 29.2 percent, and 26.6 percent respectively.

\section{Equation 1: Test of hypotheses}

\section{Model 1: Straight error as a dependent variable}

Change in past production positively and significantly influences straight errors, giving support to Hypothesis 1, which supposes ignorance of the 'regression toward the mean' phenomenon. Regarding Hypothesis 2, that investments in dynamic resources positively bias estimates, we find that relative investments in R\&D positively and significantly influence straight errors (at $p<$ 0.001). As for Hypothesis 3, self-perception also positively biases estimates (at $p<0.001$ ). Overall, organizational illusion of control is positively associated with forecast overestimation. Higher relative investments in marketing information and employee capability seem to reduce straight errors (at $p<0.01$ and $p<0.001$ ), indicating that organizational attention reduces straight errors in forecasts.

\section{Models 2-4: Absolute value of error as a dependent variable}

Before discussing Hypotheses 4-6, we note that many of the relations found to influence bias (Model 1 results) also influence absolute errors. In Models 2-4, past production positively influences absolute errors, indicating that the ignorance of 'regression toward the mean' is more likely to occur when past production grew (reinforcing positive errors). The coefficients of RelativeR\&D are either weakly positive $(p<0.1$ in Models 2 and 3) or not significant (in Model 4). While selfperception is positive and not significant in Model 2, it becomes significant in Models 3 and 4 (due to inclusion of interaction terms). However, as such Model 2 suffers from some misspecification since the interactions in Models 3 and 4 are significant, and results from Model 2 should be considered with caution. Overall, at first sight, relative investments in R\&D (only marginally) and high selfperception increase positive forecasting bias and impact slightly more on the magnitude of positive errors than of negative errors.

In agreement with Hypothesis 4 that relative investments in market information negatively influence the magnitude of forecast errors, all three models show that relative market information expenditures have a negative direct effect on absolute errors $(p<0.001)$. However, contrary to Hypothesis 5, which assumed that relative investments in employee capability negatively influence the magnitude of forecast errors, the direct effect of relatively higher expenditures in employee capability is positive and significant in Models 2-4 $(p<0.001)$. We may infer (from the negative RelEduc-Invst coefficient in Model 1) that this unexpected result appears because relative investment in employee capability tends to increase negative forecast bias.

At that stage of the analysis, some findings deserve further comments: (1) past production changes positively influence absolute errors, indicating that production growth reinforces optimism in forecasts; (2) RelativeR\&D is positively related to straight errors but its effect fades when considering absolute errors, indicating that while positive (negative) differences in $R \& D$ investments are associated with positive (negative) forecast biases, the error magnitude is not mainly driven by differences in RelativeR\&D; (3) SelfPerception clearly increases absolute errors by increasing bias; (4) Rel-Market-Info reduces significantly both straight and absolute errors, i.e., reduces optimism in estimates; (5) finally, RelEduc-Invst reduces straight errors but increases the magnitude of errors, i.e., favors pessimistic estimations.

However, as an additive model, in Model 2, the impact of RelativeR\&D and SelfPerception is the same across all levels of market information and relative investments in employee capability, while in Model 3, as an interactive model, the impact 


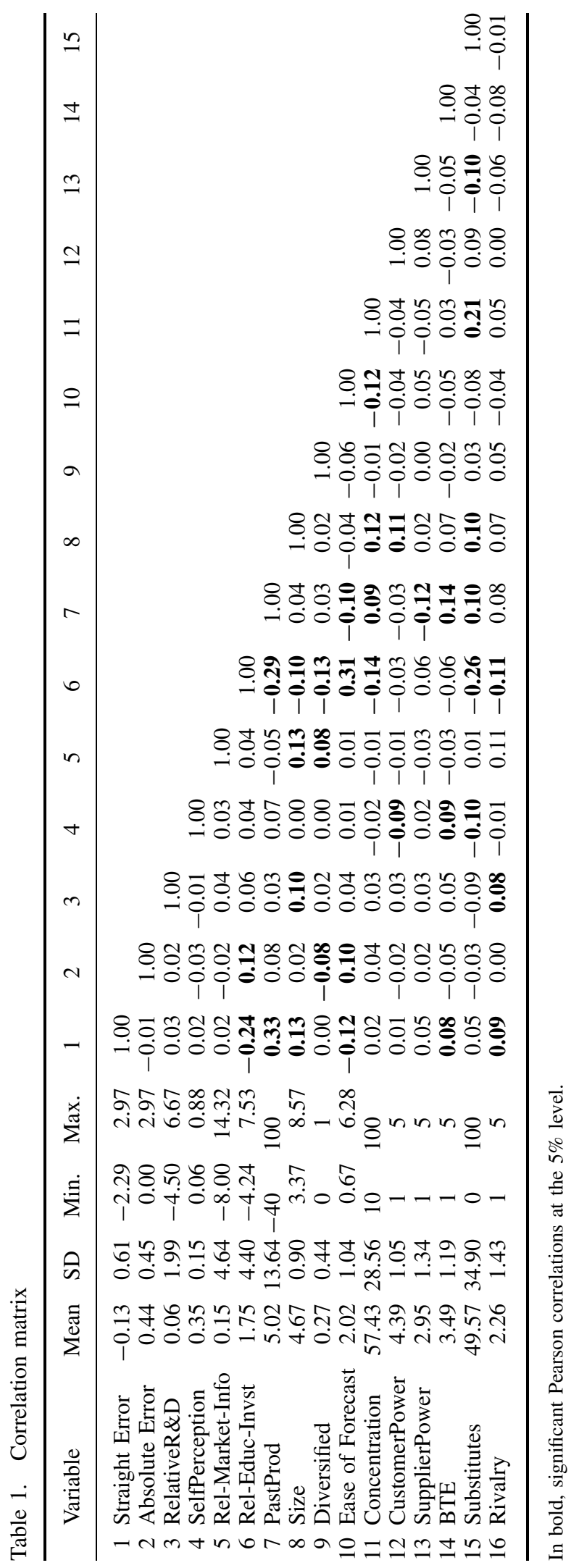


Table 2. Results of 3SLS analyses

\begin{tabular}{|c|c|c|c|c|}
\hline & $\begin{array}{l}\text { Straight errors } \\
\text { Model } 1^{\mathrm{a}}\end{array}$ & $\begin{array}{l}\text { Absolute errors } \\
\text { Model } 2^{\mathrm{a}}\end{array}$ & $\begin{array}{l}\text { Absolute errors } \\
\text { Model } 3^{\mathrm{a}}\end{array}$ & $\begin{array}{l}\text { Absolute errors } \\
\text { Model } 4^{\mathrm{a}}\end{array}$ \\
\hline Equation 1 & $N=785$ & $N=785$ & $N=785$ & $N=785$ \\
\hline Intercept & $-0.534^{* * *}(-4.91)$ & $0.151 \dagger(1.88)$ & $0.093(1.18)$ & $-0.301^{* * *}(3.20)$ \\
\hline PastProd & $0.342^{* * *}(12.04)$ & $0.164^{* * *}(5.47)$ & $0.169^{* * *}(5.68)$ & $0.272^{* * *}(7.98)$ \\
\hline RelativeR\&D & $0.243^{* * *}(8.90)$ & $0.048+(1.75)$ & $0.055 \dagger(1.82)$ & $0.016(0.44)$ \\
\hline SelfPerception & $0.156^{* * *}(5.60)$ & $0.039(1.39)$ & $0.100^{* * *}(3.42)$ & $0.129^{* * *}(3.63)$ \\
\hline Rel-Market-Info & $-0.070^{* *}(-2.55)$ & $-0.482^{* * *}(-16.78)$ & $-0.280^{* * *}(-3.70)$ & $-0.162^{* * *}(-4.72)$ \\
\hline Rel-Educ-Invst & $-0.365^{* * *}(-12.01)$ & $0.414^{* * *}(13.10)$ & $0.778^{* * *}(11.52)$ & $0.475^{* * *}(5.83)$ \\
\hline $\begin{array}{l}\text { Rel-Market-Info } \times \\
\text { RelativeR\&D }\end{array}$ & - & - & $-0.055^{*}(-1.92)$ & $-0.045(-1.27)$ \\
\hline $\begin{array}{l}\text { Rel-Market-Info } \times \\
\text { SelfPerception }\end{array}$ & - & - & $-0.204^{* *}(-2.58)$ & $-0.265^{* *}(-2.60)$ \\
\hline $\begin{array}{l}\text { Rel-Educ-Invst } \times \\
\text { RelativeR\&D }\end{array}$ & - & - & $-0.019(-0.64)$ & $-0.006(-0.17)$ \\
\hline $\begin{array}{c}\text { Rel-Educ-Invst } \times \\
\text { SelfPerception }\end{array}$ & - & - & $-0.432^{* * *}(-6.42)$ & $-0.409^{* * *}(-5.02)$ \\
\hline Size & $0.103^{* * *}(3.60)$ & $0.145^{* * *}(4.86)$ & $0.134^{* * *}(4.44)$ & $0.207^{* * *}(5.91)$ \\
\hline Diversified & $0.012(0.63)$ & $-0.014(-0.52)$ & $-0.024(-0.89)$ & $-0.049(-1.51)$ \\
\hline Ease of forecasting & $-0.042(-1.41)$ & $-0.098^{* *}(-2.83)$ & $-0.060 \dagger(-1.71)$ & $-0.076^{*}(-2.10)$ \\
\hline Concentration & $-0.023(-0.89)$ & $0.004(0.15)$ & $0.007(0.29)$ & $-0.024(-0.75)$ \\
\hline Equation 2 & RelativeR\&D & RelativeR\&D & RelativeR\&D & RelativeR\&D \\
\hline Intercept & $-1.03^{*}(-2.25)$ & $-1.49^{* * *}(-3.15)$ & $-1.51^{* * *}(-3.19)$ & $-1.16^{*}(-2.53)$ \\
\hline ErrorIGE $^{\mathrm{b}}$ & $0.254^{* * *}(6.25)$ & $0.125 \dagger(1.80)$ & $0.128 \dagger(1.85)$ & $0.236^{* * *}(3.65)$ \\
\hline Ease of forecasting & $0.013(0.37)$ & $-0.050(-1.43)$ & $-0.050(-1.43)$ & $0.013(0.39)$ \\
\hline CustomerPower & $0.092^{* *}(2.65)$ & $0.097^{* *}(2.75)$ & $0.097^{* *}(2.75)$ & $0.107^{* *}(2.88)$ \\
\hline SupplierPower & $-0.025(-0.74)$ & $-0.038(-1.04)$ & $-0.037(-1.07)$ & $-0.034(-1.00)$ \\
\hline BTE & $0.149^{* * *}(4.18)$ & $0.204^{* * *}(5.86)$ & $0.205^{* * *}(5.90)$ & $0.170^{* * *}(4.78)$ \\
\hline Rivalry & $0.015(0.43)$ & $0.058 \dagger(1.68)$ & $0.059 \dagger(1.69)$ & $0.129(0.85)$ \\
\hline Substitutes & $-0.131^{* * *}(-3.75)$ & $-0.118^{* * *}(-3.34)$ & $-0.118^{* * *}(-3.31)$ & $-0.124^{* * *}(-3.52)$ \\
\hline Equation 3 & Rel-Market-Info & Rel-Market-Info & Rel-Market-Info & Rel-Market-Info \\
\hline Intercept & $0.141(0.08)$ & $1.225^{* * *}(3.46)$ & $1.555^{* * *}(3.61)$ & $0.225(0.18)$ \\
\hline ErrorIGE $^{\mathrm{b}}$ & $-0.091 *(-2.16)$ & $-0.742^{* * *}(-10.25)$ & $-0.757^{* * *}(-10.40)$ & $-0.047(-1.23)$ \\
\hline Ease of forecasting & $-0.072 *(-1.96)$ & $-0.025(-0.66)$ & $-0.025(-0.66)$ & $-0.062 \dagger(-1.70)$ \\
\hline CustomerPower & $0.018(0.52)$ & $0.011(0.32)$ & $0.012(0.37)$ & $0.015(0.44)$ \\
\hline SupplierPower & $-0.071^{*}(-2.01)$ & $-0.061 \dagger(-1.83)$ & $-0.067^{*}(-1.97)$ & $-0.068 \dagger(-1.91)$ \\
\hline BTE & $-0.001(-0.05)$ & $-0.009(-0.28)$ & $-0.018(-0.53)$ & $-0.010(-0.78)$ \\
\hline Rivalry & $0.121^{* * *}(3.35)$ & $0.067^{*}(1.99)$ & $0.069 *(2.02)$ & $0.115^{* * *}(3.21)$ \\
\hline Substitutes & $0.114^{* * *}(3.15)$ & $0.050(1.44)$ & $0.046(1.34)$ & $0.111^{* * *}(3.09)$ \\
\hline Equation 4 & Rel-Educ-Invst & Rel-Educ-Invst & Rel-Educ-Invst & Rel-Educ-Invst \\
\hline Intercept & $2.40^{* *}(2.77)$ & $1.211(1.30)$ & $1.114(1.19)$ & $2.87^{* * *}(3.23)$ \\
\hline ErrorIGE $^{b}$ & $-0.459^{* * *}(-7.86)$ & $0.459^{* * *}(7.15)$ & $0.466^{* * *}(7.24)$ & $-0.268^{* * *}(-8.06)$ \\
\hline Ease of forecasting & $0.239^{* * *}(7.52)$ & $0.330^{* * *}(9.98)$ & $0.330^{* * *}(9.98)$ & $0.283^{* * *}(8.05)$ \\
\hline CustomerPower & $-0.046(-1.53)$ & $-0.046(-1.46)$ & $-0.046(-1.48)$ & $-0.059 \dagger(-1.91)$ \\
\hline SupplierPower & $0.015(0.52)$ & $0.032(1.04)$ & $0.036(1.14)$ & $0.029(0.95)$ \\
\hline BTE & $-0.070^{* *}(-2.28)$ & $-0.182^{* * *}(-5.84)$ & $-0.177^{* * *}(-5.64)$ & $-0.104^{* *}(-3.28)$ \\
\hline Rivalry & $-0.113^{* * *}(-3.74)$ & $-0.119^{* * *}(-3.73)$ & $-0.118^{* * *}(-3.67)$ & $-0.139^{* * *}(-4.45)$ \\
\hline Substitutes & $-0.153^{* * *}(-5.00)$ & $-0.160^{* * *}(-5.11)$ & $-0.162^{* * *}(-5.14)$ & $-0.166^{* * *}(-5.32)$ \\
\hline System weighted $R^{2}$ & $34.4 \%$ & $28.7 \%$ & $29.2 \%$ & $26.6 \%$ \\
\hline$\Delta R^{2}$ & & & $0.5 \%$ ** & \\
\hline
\end{tabular}

${ }^{a}$ All $\beta, \chi$, and $\delta$ are standardized coefficients. In parentheses, $t$-values.

${ }^{\mathrm{b}}$ In Equations 2-4 ErrorIGE is straight error for Models 1 and 4 and absolute error for Models 2 and 3.

*** $p<0.001 ;{ }^{* *} p<0.01 ;{ }^{*} p<0.05 ; \dagger p<0.1$ 
varies. Because Model 3 describes the relationships as conditional rather than general, it follows that the coefficients $\beta_{2 \text { to } 5}$ may differ between Models 2 and 3 (Friedrich, 1982). As a matter of fact, SelfPerception is significant in Model 3 $(p<0.001)$ and not significant in Model 2.

Therefore, to be exhaustive, we need to consider the conditional effects of Rel-Market-Info and RelEduc-Invst. ${ }^{6}$ In Model 3, all the coefficients for the interaction terms are negative; three out of four are significant (from $p<0.05$ to $p<0.001$ ). Therefore, it seems that high relative investment in marketing information moderates bias due to overinvestment in R\&D and inflated self-perception. High investments in employee capability also moderate an organization's self-perception effect on forecasting errors. Such interactions, which reduce error magnitude, give strong support to Hypothesis 6.

More precisely, the impact of a change in marketing information expenditures is demonstrated by the derivative of Equation 1 with respect to Rel-Market-Info:

$$
\begin{aligned}
& \mathrm{d}[\text { Equation } 1] / \mathrm{d} \text { Rel-Market-Info }=-0.280 \\
& -0.204 \text { SelfPerception }-0.055 \text { RelativeR\&D }
\end{aligned}
$$

If RelativeR\&D and SelfPerception are 0, a oneunit change in Rel-Market-Info reduces absolute error by 0.280 . Let's consider the values from the observed range of experience:

$$
\begin{aligned}
\operatorname{Min}(\text { SelfPerception }) & =0.06 \text { and } \\
\operatorname{Max}(\text { SelfPerception }) & =0.88 \\
\operatorname{Min}(\text { RelativeR\&D }) & =-4.50 \text { and } \\
\operatorname{Max}(\text { RelativeR\&D }) & =6.67
\end{aligned}
$$

The values for $\mathrm{d}[$ Equation 1]/d Rel-Market-Info are respectively: -0.04 for $(0.06 ;-4.50),-0.21$ for $(0.88 ;-4.50),-0.66$ for $(0.06 ; 6.67)$ and -0.82 for $(0.88 ; 6.67)$.

Therefore, the influence is negative throughout the range of observed data and Rel-MarketInfo reduces error magnitude (increases accuracy) both directly and through its interaction with

\footnotetext{
${ }^{6}$ We compare Model 3 with Model 2 in this section. Recall that Model 4 is given as a control for which the ErrorIGE variable in Equations 2-4 is a straight error instead of absolute errors as in Model 3. Results in Model 4 are very similar to those of Model 3, and the same reasoning applies.

SelfPerception and RelativeR\&D. This influence is close to zero for the minimum values of both variables, becomes increasingly negative with increase in either value, and reaches its maximum around -0.82 for highest values of both variables.

The impact of a change in Rel-Educ-Invst on absolute errors is the derivative of Equation 1 with respect to Rel-Educ-Invst:

$$
\begin{aligned}
& \mathrm{d}[\text { Equation } 1] / \mathrm{d} \text { Rel-Educ-Invst }=0.778 \\
& -0.432 \text { SelfPerception }-0.019 \text { RelativeR\&D }
\end{aligned}
$$

Although Hypothesis 5 predicts a negative coefficient for Rel-Educ-Invst, the result is positive. However, the interactions' coefficients with RelativeR\&D and SelfPerception are negative, as predicted by Hypothesis 6 (but not significant for RelativeR\&D). For instance, for every one-unit increase in SelfPerception, the slope of absolute errors on Rel-Educ-Invst is reduced by 0.432 .

The values for $\mathrm{d}$ [Equation 1]/d Rel-Educ-Invst inside the limits of the observed range of values are respectively: 1.60 for $(0.06 ;-4.50), 1.25$ for $(0.88 ;-4.50),-0.52$ for $(0.06 ; 6.67)$ and -0.87 for $(0.88 ; 6.67)$.

At the mean values for RelativeR\&D and SelfPerception, the impact of Rel-Educ-Invst is still worth 0.150 . At the third quartile values, the impact of Rel-Educ-Invst on absolute errors equals -0.059 , which indicates that there are few cases for which the overall impact of Rel-Educ-Invst corresponds to expectations (Hypothesis 5) and actually reduces magnitude errors. Such firms must have either a level of R\&D expenditures 4 percent greater than the industry average (last quartile of values) or a combination of high RelativeR\&D and high SelfPerception. Therefore, the influence of Rel-Educ-Invst increases the magnitude of error for the majority of observed values of both RelativeR\&D and SelfPerception but becomes negative for highest values of both variables (i.e., reduces error magnitude for these cases).

\section{Equation 1: Control variables}

Control variables indicate that: (1) company size increases straight and absolute errors. Larger firms tend to have more optimistic IGE, probably due to a bias in the causal relationship between their own size and the impact of their actions on the industry in general; (2) diversification has no direct impact 
on errors; (3) ease of industry forecasting does not reduce straight errors but marginally reduces the magnitude of both positive and negative errors $(p<0.1$ in Model 3 and $<0.05$ in Models 2 and 4). Thus, the effects of 'ease of forecasting' cancel each other out as far as error direction is concerned, but clearly impact error magnitude and (4) the coefficients for industry concentration are not significant.

\section{Findings on effects of ErrorIGE on firm investments: Equations 2-4}

Industry variables yield mixed results we do not report at length. However, some interesting findings concern the reciprocal relationships between forecast errors and firm behavior. In Equation 2, both straight and absolute errors positively influence RelativeR\&D. Straight error is significant at $p<0.001$ and absolute error at $p<0.1$, indicating that optimistically evaluating next year's industry growth is likely to bring about higher relative current R\&D investments. In Equation 3, the negative influence of both errors on Rel-Market-Info suggests an inverse relationship between both error direction and error magnitude and a firm's relative investment in marketing information. Thus, optimistic evaluations of industry growth tend to reduce firms' investments in organizational attention, in accordance with previous studies (Bateman and Zeithaml, 1989; Thomas et al., 1993; Simon, Houghton, and Aquino, 2000). In Equation 4, the coefficient of the effect of straight errors on Rel-Educ-Invst, which is significant and negative in Models 1 and 4, indicates that positive bias reduces relative investment in Rel-Educ-Invst, i.e., employee capability. However, the greater the absolute value of error, the higher the relative investment in employee capability, since the coefficient for ErrorIGE is significant and positive in Models 2 and 3. Consequently, highly pessimistic IGE induces firms to invest in employee capability, while optimistic IGE does not.

\section{DISCUSSION}

In this paper, we examine forecasting ability at the organizational level while simultaneously studying the direct effects of illusion of control and attention and their interactions on both forecasting biases and absolute value of errors. More precisely, we answer our two research questions: (1) what are the firm's characteristics that influence its forecasting ability? and (2) how do organizational illusion of control and organizational attention impact forecasting biases and the magnitude of errors?

First, there is an observable ignorance of the 'regression toward the mean' effect, since past production growth implies positively biased forecasts, and increases absolute value of errors.

Next, a firm's illusion of control, manifested by higher relative investments in dynamic resources and high self-perception, increases positive forecast biases. It also tends to increase absolute value of errors as the positive and significant coefficients of SelfPerception and RelativeR\&D (even if less so) demonstrate.

Moreover, organizational attention to external information, manifested by higher relative investments in marketing information, reduces positive forecast biases and the magnitude of errors. It also significantly moderates forecast biases associated with illusion of control, resulting in improved accuracy.

Finally, organizational attention to internal information, manifested by higher relative investments in employee education, increases negative forecast bias and reduces average absolute error only for the highest observed values of illusion of control. For the majority of the observed values of RelativeR\&D and SelfPerception, the overall influence of Rel-Educ-Invst increases average absolute error, probably because high relative education expenditures, which correspond to higher attention to internal information, knowledge flows, and increased organizational sensitivity to negative signals favor pessimism (Bateman and Zeithaml, 1989).

Some years ago, Starbuck and Mezias (1996) expressed concern about the empirical challenge of testing accuracy in perceptions. We believe that we have partially tackled the empirical problem, at least in the circumscribed domain of organizational forecasting ability, as well as addressed the suggestion of causal circularity. By controlling for reciprocal effects, we show not only the differentiated relationships between firm characteristics and forecast errors, but also incidentally how these errors affect relative investments in dynamic resources, marketing information, and employee capability (Equations 2-4). Further, we correct a tendency to empirically focus on overevaluation and hubris (Hayward and Hambrick, 1997; Coff, 1999). Finally, reinforcing Makadok and Walker's 
(2000) study, these findings suggest not only the influences of organizational characteristics on a firm's forecasting ability, but show which organizational factors lead firms with similar views to estimate their industry potential differently. In a sense, this paper analyzes the determinants of firms' varied perceptions of a shared reality (i.e., industry environment), to which each firm contributes and that derives from their actions.

Yet, there were some limitations, such as using secondary data to test our hypotheses. Although we controlled for respondents' biases externally (through the kappas), it was not possible to perform an internal cross-evaluation of organizational perceptions (an intrinsic but regrettable limitation of studies using secondary data). However, as the Bank of France has increased the reliability of its survey over the years, using welltrained interviewers and specialists in econometrics to insure data quality, we are rather confident that our results can be generalized (see preceding studies by Cool and Henderson, 1998). The use of subjective data may also raise concerns. Notably, CEOs provided the estimates, and not the organization per se. However, the survey question does not ask a personal estimate but a firm's estimate, since it appears in a section where all the information relates to the firm's industry characteristics. Also, the question in itself should not entice CEOs to substitute personal judgment for their roles as heads of firms - as might ethical questions, opinion, or advice. Therefore, the use of subjective data is as valuable in this study as it is for the evaluation of strategic issues (Hambrick, 1981, 1982; Starbuck and Mezias, 1996). Additional data that could have improved the precision of the specific indicators were not available (e.g., information concerning the quality of human resources 'stock' variables could have improved the test of Hypothesis 5). A data series longer than our 1-year study may provide further insights on the durability of organizational illusion of control and organizational attention effects on forecasting ability (i.e., the 'measurement problem'; Makadok and Walker, 2000).

As for management, top managers must be aware of the influence of their organizations when developing estimates and making decisions. We cannot suggest explicit recommendations in terms of resource investment for reducing illusion of control or increasing attention. However, beyond the technical recommendations drawn from the forecasting literature on judgmental estimations, many actions may improve a firm's estimation capability and corollary decisions (e.g., Ocasio's, 1997, 'attention management'), which relate to organizational investments in terms of market information collection and treatment and employee capability management. Altogether, these factors may help a firm to better judge its environmental conditions as well as evaluate its own resourcefulness.

Our findings can lead to other research topics. First, in addition to industry growth estimates, we might extend our hypotheses on illusion of control and attention to other elements for which firms have to estimate potential value, such as a resource (Barney, 1986, 1991). Organizational illusion of control could lead to both overvaluing a firm's resources and undervaluing a competitor's. By the same token, a firm's attention to external information and internal knowledge may (1) correct the tendency to overrate and (2) increase the likelihood of finding undervalued resources in the environment. In this respect, organizational forecasting ability is utterly a strategic and distinctive competence. Such an ability should correspond to the definition of a capable organization which, in association with a competitive advantage, imply above-average performance (see the Powell, 2001-Durand, 2002, debate).

Second, it would be interesting to relate these results on estimating errors to performance. Do firms that minimize errors in estimation obtain better performance results? Do organizational illusion of control and organizational attention play different roles in performance? Linking the accuracy of estimates with performance indicators to uncover the chain of causes and effects from resource endowment, firm perception, and performance would further advance research.

\section{ACKNOWLEDGEMENTS}

I would like to thank the two anonymous reviewers as well as Rich Makadok, Elaine Mosakowski, and Michael Lubatkin for their comments on former versions of this paper. I would also like to thank Robert Kazanjian and the participants of the SMS Conference 2001 who gave me advice for the pursuit of this research. I acknowledge the support of the Bank of France Service de Methodologie

Strat. Mgmt. J., 24: 821-838 (2003) 
and Régis Coeurderoy for his continuing encouragement. Finally, I dedicate this paper in memory of Roland Calori, who supported this research and gave me invaluable clues in developing it.

\section{REFERENCES}

Amburgey T, Dacin T. 1997. Event count analysis and strategic management. In Statistical Models for Strategic Management, Ghertman M, Obadia J, Arregle J-L (eds). Kluwer: Boston, MA; 29-45.

Bandura A. 1977. Self-efficacy: toward a unifying theory of behavioral change. Psychological Review 84(2): 191-215.

Barnes JH. 1984. Cognitive biases and their impact on strategic planning. Strategic Management Journal 5(2): $129-137$.

Barney J. 1986. Strategic factor markets: expectations, luck, and business strategy. Management Science 42: 1231-1241.

Barney J. 1991. Firm resources and sustained competitive advantage. Journal of Management 17: 99-120.

Bateman TS, Zeithmal CP. 1989. The psychological context of strategic decisions: a model and convergent experimental findings. Strategic Management Journal 10(1): 59-74.

Beyer J, Chattopadhyay P, George E, Glick WH, Pugliese D. 1997. The selective perception of managers revisited. Academy of Management Journal 40: 716-737.

Brews PJ, Hunt MR. 1999. Learning to plan and planning to learn: resolving the planning school/learning school debate. Strategic Management Journal 20(10): 889-914.

Bromiley P. 1987. Do forecasts produced by organizations reflect anchoring and adjustment? Journal of Forecasting 6(3): 201-210.

Bourgeois LJ. 1985. Strategic goals, perceived uncertainty, and economic performance in volatile environments. Academy of Management Journal 28: $548-573$.

Carleton WT, Chen CR, Steiner TL. 1998. Optimism biases among brokerage and non-brokerage firms' equity recommendations: agency costs in the investment industry. Financial Management 27(1): $17-30$.

Chattopadhyay P, Glick WH, Miller CC, Huber GP. 1999. Determinants of executive beliefs: comparing functional conditioning and social influence. Strategic Management Journal 20(8): 763-789.

Clapham SE, Schwenk CR. 1991. Self-serving attributions, managerial cognition, and company performance. Strategic Management Journal 12(3): 219-229.

Cockburn IM, Henderson RM, Stern S. 2000. Untangling the origins of competitive advantage. Strategic Management Journal, Special Issue 21: 1123-1145.

Coff RW. 1999. How buyers cope with uncertainty when acquiring firms in knowledge-intensive industries: caveat emptor. Organization Science 10: 144-161.
Cool K, Henderson J. 1998. Power and firm profitability in supply chains: French manufacturing industry in 1993. Strategic Management Journal 19(10): 909-926.

Corner P, Kinicki A, Keats B. 1994. Integrating organizational and individual information processing perspectives on choice. Organization Science 5(3): 294-309.

Daft R, Weick K. 1984. Toward a model of organizations as interpretation systems. Academy of Management Review 9(2): 284-295.

Das TK, Teng BS. 1999. Cognitive biases and strategic decision processes: an integrative perspective. Journal of Management Studies 36: 757-778.

Duhaime I, Schwenk C. 1985. Conjectures on cognitive simplification in acquisition and divestment decision making. Academy of Management Review 10: 287-295.

Durand R. 2002. Competitive advantages exist: a response to Powell. Strategic Management Journal 23(9): 867-872.

Eisenhardt K, Martin JA. 2000. Dynamic capabilities: what are they? Strategic Management Journal, Special Issue 21: 1105-1121.

Friedrich RJ. 1982. In defense of multiplicative terms in multiple regression equations. American Journal of Political Science 26: 797-833.

Garud R, Rappa M. 1994. A socio-cognitive model of technology evolution: the case of cochlear implants. Organization Science 5(3): 344-362.

Grant RM. 1998. Prospering in dynamically competitive environments: organizational capability as knowledge integration. In Illinitch A, Lewin A, D'aveni R (eds). Managing in Times of Disorder. Sage: London; 297-318.

Greve H. 1996. Patterns of competition: the diffusion of a market position in radio broadcasting. Administrative Science Quarterly 41: 29-60.

Greve H. 1998. Managerial cognition and the mimetic adoption of market positions: what you see is what you do. Strategic Management Journal 19(10): 967-988.

Greve H. 1999. The effect of core change on performance: inertia and regression toward the mean. Administrative Science Quarterly 44: 590-614.

Halman J, Keizer J. 1994. Diagnosing risk in product innovation projects. International Journal of Project Management 12(2): 75-81.

Hambrick DC. 1981. Strategic awareness within top management teams. Strategic Management Journal 2(3): $153-173$.

Hambrick DC. 1982. Environmental scanning and organizational strategy. Strategic Management Journal 3(2): $159-174$.

Hayward ML, Hambrick DC. 1997. Explaining premium paid for large acquisitions: evidence of CEO hubris. Administrative Science Quarterly 42(1): 103-127.

Henderson RM, Cockburn IM. 1994. Measuring competence? Exploring firm effects in pharmaceutical research. Strategic Management Journal, Winter Special Issue 15: 63-84.

Kahneman D, Tversky A. 1984. Choice, values, and frames. American Psychologist 39: 341-350. 
Kennedy P. 1998. A guide to Econometrics. MIT Press: Cambridge, MA.

Knight D, Pearce CL, Smith KG, Olian JD, Sims HP, Smith KA, Flood P. 1999. Top management team diversity, group process, and strategic consensus. Strategic Management Journal 20(5): 445-465.

King AW, Zeithaml CP. 2001. Competencies and firm performance: examining the causal ambiguity paradox. Strategic Management Journal 22(1): 75-99.

Landis RJ, Koch GG. 1977. The measurement of observer agreement for categorical data. Biometrics 33: $159-174$.

Langer EJ. 1975. The illusion of control. Journal of Personality and Personal Psychology 32(2): 311-328.

Lubatkin M, Schulze W, Mainkar A, Cotterill RW. 2001. Ecological investigation of firm-effect in horizontal mergers. Strategic Management Journal 22(4): $335-357$.

Makadok R, Walker G. 2000. Identifying a distinctive competence: forecasting ability in the money fund industry. Strategic Management Journal 21(8): 853-864.

Matute H. 1996. Illusion of control: detecting responseoutcome independence in analytic but not in naturalistic conditions. Psychological Science 7(5): 289-299.

McNamara G, Bromiley P. 1997. Decision making in an organizational setting: cognitive and organizational influences on risk assessment in commercial lending. Academy of Management Journal 40(5): 1063-1088.

McNamara G, Bromiley P. 1999. Risk and return in organizational decision making. Academy of Management Journal 42(3): 330-339.

McNamara G, Vaaler P. 2000. The influence of competitive positioning and rivalry on emerging market risk assessment. Journal of International Business Studies 31(2): 337-347.

McNamara G, Luce RA, Tompson GH. 2002. Examining the effect of complexity in strategic group knowledge on firm performance. Strategic Management Journal 23(2): 153-170.

Mosakowski E. 1997. Strategy making under causal ambiguity: conceptual issues and empirical evidence. Organization Science 8(4): 414-442.

Mosakowski E. 1998a. Managerial prescriptions under the resource-based view of strategy: the example of motivational techniques. Strategic Management Journal 19(12): 1169-1182.

Mosakowski E. 1998b. Entrepreneurial resources, organizational choices, and competitive outcomes. Organization Science 9(6): 625-643.

Mosakowski E, McKelvey B. 1997. Predicting rent generation in competence-based competition. In Competence-Based Strategic Management, Sanchez R, Heene A (eds). Wiley: New York; 65-83.

Nelson R, Winter S. 1982. An Evolutionary Theory of Economic Change. Harvard University Press: Boston, MA.

Ocasio W. 1997. Towards an attention-based view of the firm. Strategic Management Journal, Summer Special Issue 18: 187-206.
Penrose E. 1959. The Theory of the Growth of the Firm. Basil Blackwell: Oxford.

Pindyck RS, Rubinfeld DL. 1981. Econometric Models and Economic Forecast. McGraw-Hill: New York.

Powell T. 1992. Organizational alignment as competitive advantage. Strategic Management Journal 13(2): $119-134$.

Powell T. 2001. Competitive advantage: logical and philosophical considerations. Strategic Management Journal 22(9): 875-888.

Prahalad CK, Bettis R. 1986. The dominant logic: a new linkage between diversity and performance. Strategic Management Journal 7(6): 485-502.

Scherer FM, Ross D. 1990. Industrial Market Structure and Economic Performance, 3rd edn. Houghton Mifflin: Boston, MA.

Schweitzer M, Cachon G. 2000. Decision bias in the newsvendor problem with a known demand distribution: experimental evidence. Management Science 46: 404-420.

Schwenk CR. 1984. Cognitive simplification processes in strategic decision-making. Strategic Management Journal 5(2): 111-128.

Schwenk CR. 1986. Information, cognitive biases, and commitment to a course of action. Academy of Management Review 11: 298-310.

Simon M, Houghton SM, Aquino K. 2000. Cognitive biases, risk perception, and venture formation: how individuals decide to start companies. Journal of Business Venturing 15(2): 113-134.

Simon M, Houghton SM, Savelli S. 2000. The effects of overconfidence on the performance of product introductions: evidence from an exploration field study. Paper presented at the Academy of Management, Toronto.

Starbuck WH, Mezias J. 1996. Opening Pandora's box: studying the accuracy of managers' perceptions. Journal of Organizational Behavior 17: 99-117.

Staw BM, Ross J. 1987. Behaviors in escalation situations: antecedents, prototypes, and solutions. In Research in Organizational Behavior, Cummings LG, Staw B (eds). JAI Press: Greenwich, CT; 39-78.

Sutcliffe KM. 1994. What executives notice: accurate perceptions in top management teams. Academy of Management Journal 37: 1360-1378.

Sutcliffe KM, Huber GP. 1998. Firm and industry as determinants of executive perceptions of the environment. Strategic Management Journal 19(8): 793-807.

Teece DJ, Pisano G, Shuen A. 1997. Dynamic capabilities and strategic management. Strategic Management Journal 18(7): 509-553.

Theil H. 1971. Principles of Econometrics. Wiley: New York.

Thomas JB, Clark SM, Gioia D. 1993. Strategy sensemaking and organizational performance: linkages among scanning, interpretation, action, and outcomes. Academy of Management Journal, 36(2): 239-270.

Trispas M, Gavetti G. 2000. Capabilities, cognition, and inertia: evidence from digital imaging. Strategic Management Journal, Special Issue 21: 1147-1161.

Tversky A, Kahneman D. 1974. Judgement under uncertainty: heuristics and biases. Science 185: 1124-1131. 
Wonnacott R, Wonnacott T. 1972. Introductory Statistics. Wiley: New York.

Wood RE, Bandura B. 1989. Social cognitive theory of organizational management. Academy of Management Review 14(2): 361-384.

Yates JR, Jagacinski CM, Faber MD. 1978. Evaluation of partially described multiattribute options. Organizational Behavior and Human Performance 21: 240-251.

\section{APPENDIX}

\section{Organizational illusion of control}

\section{Relative $\& \& D$}

Firm R\&D expenditures (\% of sales) minus industry average R\&D expenditures (NACE 4-digit level).

\section{SelfPerception}

SelfPerception corresponds to a weighted average of a firm's perceived strength on identified success factors:

$$
\text { SelfPerception }=\Sigma\left[(\text { Strength } \times \mathrm{KSF})_{i} / 5\right]
$$

where $i$ indexes the firm.

$K S F$ is the answer to the question: Among the following variables, indicate those which are the most valorized in your industry (multiple binary answers):
1. cost/price
3. technical performance
2. quality
5. delays, responsiveness
4. reputation
7. proximity
6. services

Strength is the answer to the following question: Among the following variables, indicate your relative strength vis-à-vis your competition (5-point scale, with 5 a very high advantage):

Same items as before

\section{Organizational attention}

\section{Rel-Market-Info}

Firm marketing expenditures ( $\%$ of sales) minus industry average marketing expenditures (NACE 4-digit level).

\section{Rel-Educ-Invst}

Firm education and training expenditures (\% of overall salary expenses) minus industry average education and training expenditures (NACE 4-digit level).

\section{Other variables}

\section{SupplierPower}

Your main suppliers have a high bargaining power that enables them to negotiate contracts:

$$
\begin{array}{ccccc}
\text { strongly disagree } & & \multicolumn{2}{c}{\text { strongly agree }} \\
1 & 2 & 3 & 4 & 5
\end{array}
$$

\section{CustomerPower}

Your customers have a high bargaining power that enables them to negotiate contracts:

$$
\begin{array}{ccccc}
\text { strongly disagree } & & \multicolumn{2}{c}{\text { strongly agree }} \\
1 & 2 & 3 & 4 & 5
\end{array}
$$

\section{Rivalry}

Companies in your industry frequently modify their offering (every 2 years)

$$
\begin{array}{ccccc}
\text { strongly disagree } & & \multicolumn{2}{c}{\text { strongly agree }} \\
1 & 2 & 3 & 4 & 5
\end{array}
$$

\section{BTE}

Barriers to Entry(BTE) is the average answer to the following questions:

1. The difficulties for new competitors in reaching a sufficient plant size are:

$\begin{array}{ccccc}\text { weak } & & & & \text { strong } \\ 1 & 2 & 3 & 4 & 5\end{array}$

2. The difficulties for new competitors in reaching a sufficient cumulated volume of production are (same scale)

3. The difficulties for new competitors in having access to your production technologies are (same scale)

4. The difficulties for new competitors in finding equivalent conditions of raw material or component access are (same scale) 
5. The difficulties for new competitors in reaching a similar labor productivity level are (same scale)

\section{Substitutes}

Proxy for the threat of substitutes, with the idea that the higher the percentage of standardized products, the higher the likelihood of substitution. Therefore, Substitutes is the answer to the following question: 'What is the percentage of standardized products in your activity? 
Copyright of Strategic Management Journal is the property of John Wiley \& Sons, Inc. / Business. The copyright in an individual article may be maintained by the author in certain cases. Content may not be copied or emailed to multiple sites or posted to a listserv without the copyright holder's express written permission. However, users may print, download, or email articles for individual use. 